\title{
Molecular mechanisms of coronavirus RNA capping and methylation
}

\author{
Yu Chen ${ }^{\bowtie}$, Deyin Guo
}

State Key Laboratory of Virology, College of Life Sciences, Wuhan University, Wuhan 430070, China

The 5'-cap structures of eukaryotic mRNAs are important for RNA stability, pre-mRNA splicing, mRNA export, and protein translation. Many viruses have evolved mechanisms for generating their own cap structures with methylation at the N7 position of the capped guanine and the ribose 2'-Oposition of the first nucleotide, which help viral RNAs escape recognition by the host innate immune system. The RNA genomes of coronavirus were identified to have $5^{\prime}$-caps in the early 1980s. However, for decades the RNA capping mechanisms of coronaviruses remained unknown. Since 2003, the outbreak of severe acute respiratory syndrome coronavirus has drawn increased attention and stimulated numerous studies on the molecular virology of coronaviruses. Here, we review the current understanding of the mechanisms adopted by coronaviruses to produce the 5'cap structure and methylation modification of viral genomic RNAs.

\section{KEYWORDS coronavirus; RNA capping; triphosphatase; guanylyltransferase; methyltransferase; cap structure; methylation}

\section{INTRODUCTION}

Coronaviruses (CoVs) are the etiological agents of respiratory, gastrointestinal, hepatic, and central nervous system diseases in humans, livestock, and wild animals. Bats were reported as the natural carrier of various $\mathrm{CoVs}$ (Li et al., 2005; Wang et al., 2006; Ge et al., 2013), and some CoVs could transmit from animals to humans such as severe acute respiratory syndrome (SARS)-CoV and Middle East respiratory syndrome (MERS)-CoV (Enserink, 2003; Martina et al., 2003; Cauchemez et al., 2013; Mizutani, 2013). Therefore, CoVs are important pathogens that threaten human health.

As increased numbers of CoVs were identified, the Coronavirinae subfamily was divided into four genera: Alphacoronavirus, Betacoronavirus, Gammacoronavir-

Received: 15 January 2016, Accepted: 25 January 2016

Published online: 2 February 2016

$\triangle$ Correspondence:

Yu Chen, Phone: +86-27-68753392,

Email: chenyu@whu.edu.cn

ORCID: 0000-0003-1300-4652

Deyin Guo, Phone: +86-27-68752506,

Email: dguo@whu.edu.cn

ORCID: 0000-0002-8297-0814 us, and Deltacoronavirus (Adams and Carstens, 2012). These genera are classified with Torovirus into the family Coronaviridae of the order Nidovirales, which also includes the Arteriviridae and Roniviridae families (Gonzalez et al., 2003; Gorbalenya et al., 2006). CoVs are enveloped and possess the largest and most complex genome $(27-31 \mathrm{~kb})$ among positive-stranded RNA viruses. The genomic RNA of CoVs is polycistronic with two large open reading frames (ORFs) $1 \mathrm{a}$ and $1 \mathrm{~b}$ occupying the 5 '-proximal two-thirds of the genome. These ORFs encode the viral replicase/transcriptase and are translated directly from the genomic RNA (Figure 1), with translation of ORF $1 b$ by -1 ribosomal frameshifting at the end of ORF1a (Brierley et al., 1989). The remaining third of the $\mathrm{CoV}$ genome contains a varied number of ORFs encoding structural and virus-specific accessory proteins, which are expressed from a nested set of subgenomic RNAs that are co-terminal to both 3'- and 5'temini of the genome and synthesized by discontinuous transcription (Thiel et al., 2003; Zuniga et al., 2004; Hussain et al., 2005). The large polypeptides translated from ORF $1 \mathrm{a}$ and $1 \mathrm{~b}$ are processed by two viral proteinases (Ziebuhr, 2004) into 16 non-structural proteins (nsps) (Figure 1), such as the RNA-dependent RNA poly- 

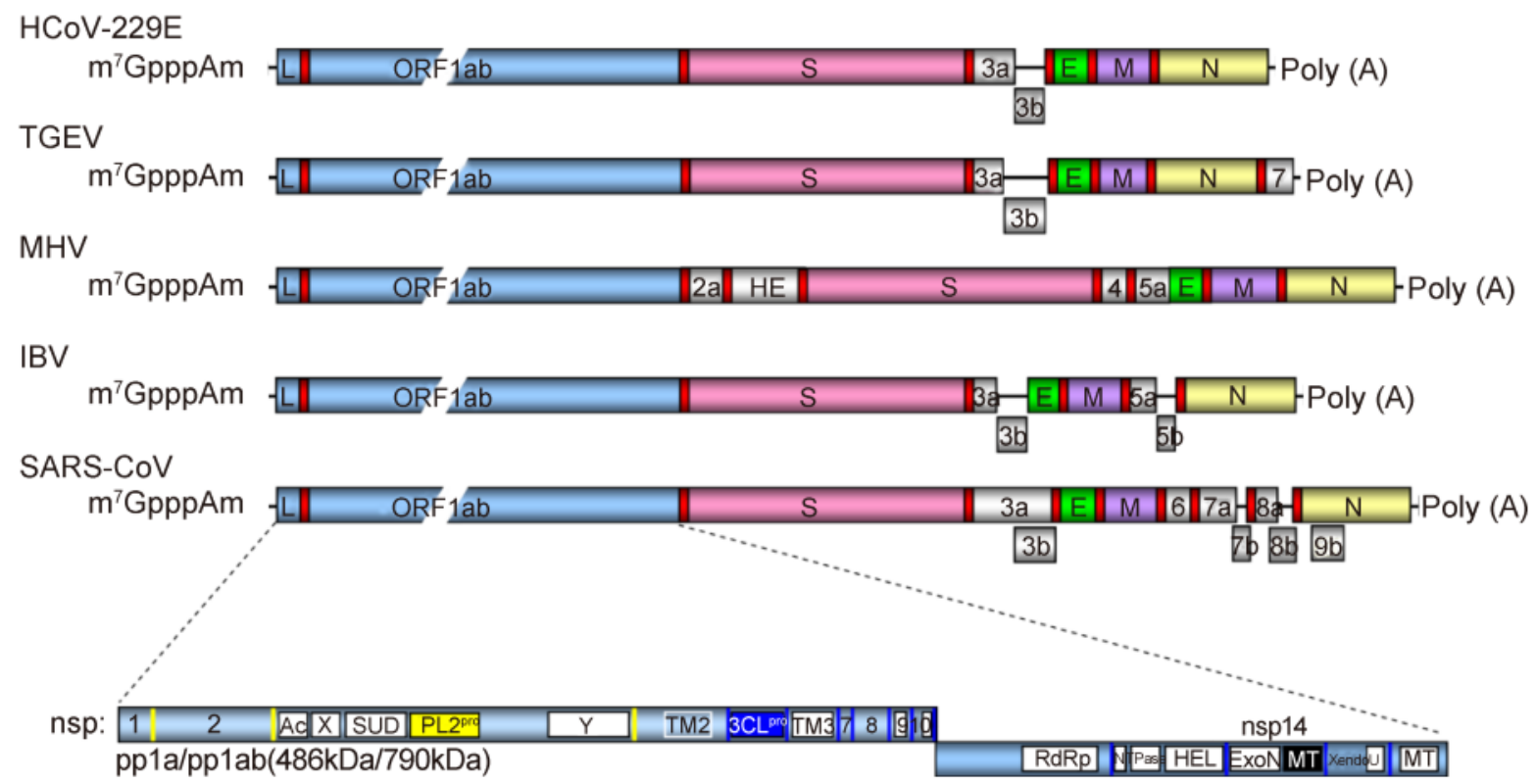

Figure 1. Comparison of the genome organization of human coronavirus 229E (HCoV-229E), transmissible gastroenteritis virus (TGEV), murine hepatitis virus (MHV), infectious bronchitis virus (IBV), and SARS-CoV. The genes and elements are depicted. ORF1a and $1 \mathrm{~b}(\mathrm{ORF} 1 \mathrm{ab})$ are indicated by a blue box. The positions of the leader sequence (L) and transcription-regulatory sequences (TRSs) are indicated by "L" and red boxes, respectively. Structure proteins are marked: S, spike protein; E, envelope protein; M, membrane protein; N, nucleocapsid protein. Vertical bars represent sites in the corresponding replicase polyprotein 1a and 1ab (pp1a/pp1ab) that are cleaved by papain-like proteinases (yellow) or the 3C-like proteinase (blue). Nsps are marked with their corresponding numbers or one of the following: SUD, SARS-CoV unique domain; $P L 2^{\text {pro }}$, papain-like cysteine proteinase; TM, transmembrane domain; $3 \mathrm{CL}^{\text {pro }}, 3 \mathrm{C}^{-l i k e}$ proteinase; RdRp, RNA-dependent RNA polymerase; NTPase, nucleoside triphosphatase; HEL, helicase; ExoN, 3'-5' exonuclease; MT, methyltransferase; XendoU, poly(U)-specific endoribonuclease.

merase (nsp12) (Imbert et al., 2006) and its co-factors (nsp7 and nsp8) (te Velthuis et al., 2012), RNA helicase and triphosphatase (nsp13) (Tanner et al., 2003; Ivanov et al., 2004), exoribonuclease (nsp14) (Minskaia et al., 2006; Chen et al., 2007) and co-factor (nsp10) (Bouvet et al., 2012), N7-methyltransferase (nsp14) (Chen et al., 2009), endonuclease (nsp15) (Bhardwaj et al., 2004; Joseph et al., 2007), and 2'-O-methyltransferase (nsp16) and co-factor (nsp10) (Decroly et al., 2008; Chen et al., 2011; Decroly et al., 2011). These nsps are involved in RNA replication/transcription, processing, and capping, a few of which, such as nsp14 (as exoribonuclease and N7-methyltransferase) and nsp15 (as endonuclease), are unique in Coronaviridae and not encoded by small RNA viruses (Prentice et al., 2004; Sawicki et al., 2005; Sevajol et al., 2014).

The 5'-ends of eukaryotic cellular mRNAs possess a cap structure, in which an N7-methylguanine $\left(\mathrm{m}^{7} \mathrm{G}\right)$ moiety is linked to the first transcribed nucleotide by a $5^{\prime}-5^{\prime}$ triphosphate bridge (Shatkin, 1976; Banerjee, 1980) (Figure 2). This cap structure plays important roles in pre-mRNA splicing, mRNA export, RNA stability by blocking degradation by the $5^{\prime}-3^{\prime}$ exoribonuclease $($ ExoN), translational initiation by promoting eukaryotic translation initiation factor 4E (eIF4E) binding (Darnell, 1979; Schwer et al., 1998; Furuichi and Shatkin, 2000), and escaping the recognition of the cellular innate immune system (Nallagatla et al., 2008). Host and viral RNA molecules lacking the 5'-cap structure are degraded in cytoplasmic granular compartments (processing bodies) (Liu and Kiledjian, 2006). The cap-0 structure of mRNA is co-transcriptionally formed through sequential enzymatic reactions (Shuman, 2001). First, an RNA triphosphatase (TPase) removes the $\gamma$ phosphate group from the 5 '-triphosphate end $(\mathrm{pppN})$ of the nascent mRNA chain to generate the diphosphate 5'ppN. Subsequently, an RNA guanylyltransferase (GTase) covalently links with the $\alpha$-phosphate of GTP to form an enzyme-GMP intermediate (Gp-En) and releases pyrophosphate (PPi). The Gp-En then transfers GMP to the $5^{\prime}$-ppN to yield the cap core structure $(\mathrm{GpppN})$ and reactivate GTase. These two-step reaction associated with GTase is reversible in the absence of the subsequent methylation step (Ray et al., 2006). Therefore, after GpppN formation, a (guanine-N7)-methyltransferase (N7-MTase) methylates the capping guanylate at the N7 position to produce a cap-0 structure $\left(\mathrm{m}^{7} \mathrm{GpppN}\right)$ (Furuichi and Shatkin, 2000). While lower eukaryotes, includ- 


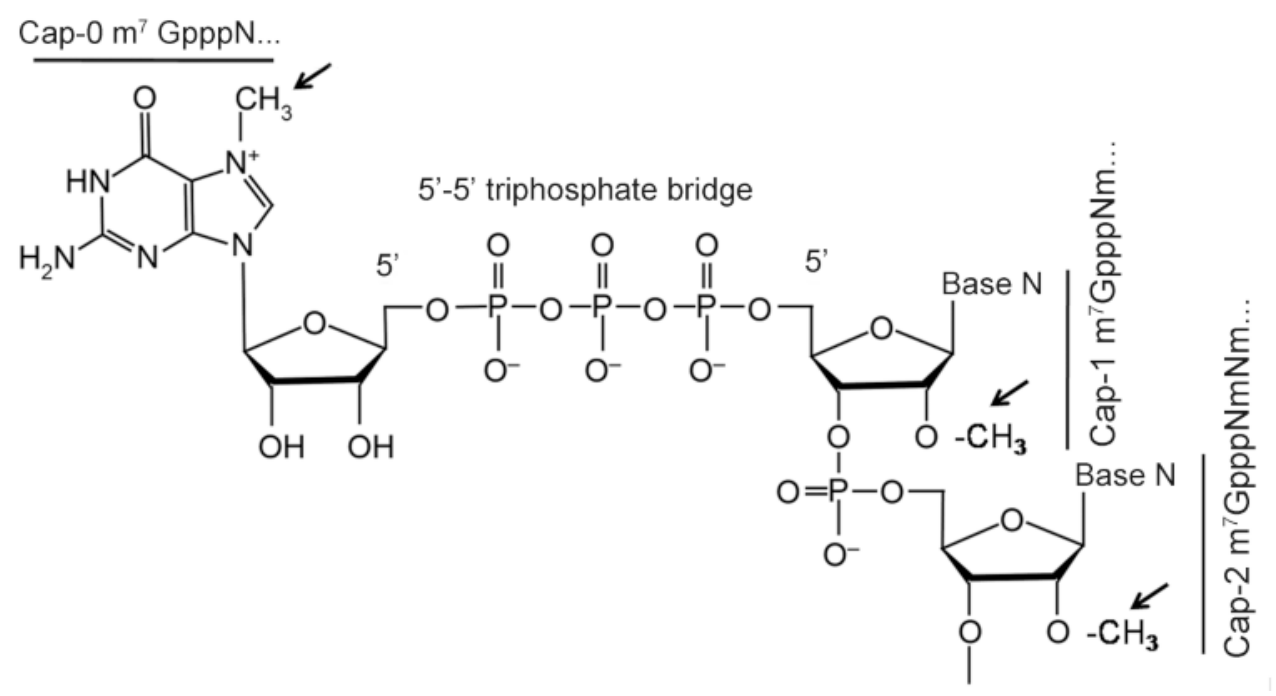

Figure 2. Structure of $5^{\prime}$-end capped mRNAs. The cap-0, cap-1, and cap-2 structures and 5'-5' triphosphate bridge are indicated. The corresponding positions of methylation are indicated by arrows. Base $\mathrm{N}$, any base linked with the ribose.

ing yeast, employ a cap- 0 structure, the cap- 0 structure in higher eukaryotes usually undergoes further methylation at the ribose $2^{\prime}-O$ position of the first and second nucleotide of the mRNA via a ribose 2 '-O-methyltransferase $\left(2^{\prime}-O\right.$-MTase) to form cap-1 ( $\left.\mathrm{m}^{7} \mathrm{GpppNm}\right)$ and cap-2 ( $\mathrm{m}^{7} \mathrm{GpppNmpNm}$ ) structures, respectively (Furuichi and Shatkin, 2000; Cowling, 2010) (Figure 3). Both N7MTase and 2'-O-MTase can catalyze transfer of a methyl group from the methyl donor S-adenosyl-L-methionine (SAM or AdoMet) (Figure 4A) to the RNA substrate, generating S-adenosyl-L-homocysteine (SAH or AdoHcy) as a byproduct (Figure 4B).

All viruses use the translational machinery of host cells. With the exception of some viruses, such as picornaviruses and hepatitis $\mathrm{C}$ virus, that circumvent the capping problem by using an internal ribosome entry site

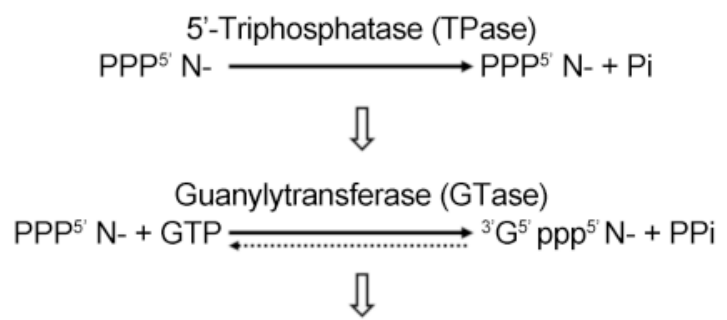

Guanine-N7-methyltransferase (N7-MTase)

$\mathrm{SAM}+{ }^{3} \mathrm{G}^{5} \mathrm{ppp}^{5} \mathrm{~N}-\longrightarrow \mathrm{m}^{7} \mathrm{G}^{5} \mathrm{ppp}^{5} \mathrm{~N}-+\mathrm{SAH}$

Nucleoside-2'-O-methyltransferase (2'-O-MTase)

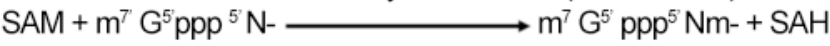

Figure 3. Reaction scheme of conventional mRNA capping. Solid arrows represent the direction of reactions. The dotted arrow indicates the reversible reaction. Unfilled arrows show the reaction sequence.
(IRES) for mRNA translation (Pelletier and Sonenberg, 1988; Tsukiyama-Kohara et al., 1992; Martinez-Salas et al., 2012), viruses targeting eukaryotes have evolved diverse strategies for capping their mRNAs to allow capdependent translation (Decroly et al., 2012; Furuichi, 2015). DNA viruses and retroviruses replicate in the nucleus by using cellular capping machinery to cap their RNAs, while the segmented negative-sense RNA viruses of the families Bunyaviridae and Orthomyxoviridae employ a unique cap-snatching mechanism to procure the mRNA cap from cellular RNA transcripts (Jin and Elliott, 1993; Leahy et al., 1997). Many viruses that replicate in the cytoplasm and do not have access to the cellular capping machinery encode their own RNA capping apparatus (Furuichi and Shatkin, 2000). Although the final cap structures of viral mRNAs are similar, the molecular organization and biochemical mechanisms of the viral capping machineries vary among different virus groups. For example, alphaviruses employ a non-canonical pathway for mRNA capping in which GTP is methylated at $\mathrm{N} 7$ before being transferred to the $5^{\prime}-\mathrm{ppN}$ of viral RNAs (Ahola and Kaariainen, 1995) (Figure 5), and vesicular stomatitis virus (VSV) uses a unique RNA:GDP polyribonucleotidyl transferase, instead of the conventional capping enzyme GMP:RNA GTase, to transfer a monophosphorylated RNA onto GDP (Ogino and Banerjee, 2007). In this review, we summarize the current knowledge on RNA capping mechanisms and RNA methylation in CoVs.

\section{DISCOVERY OF CORONAVIRUS RNA CAP STRUCTURE}

In 1981, Lai and Stohlman first reported that the murine hepatitis virus (MHV), which belongs to the genus Betacoronavirus, has a cap structure (Lai and Stohlman, 
A

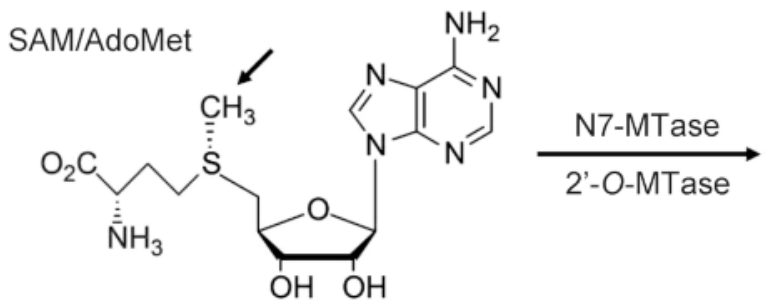

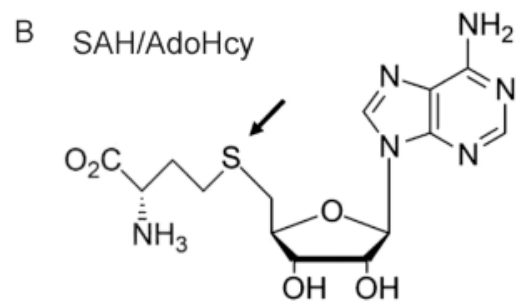

Figure 4. The structure of S-adenosyl-L-methionine (SAM or AdoMet) (A) and S-adenosyl-L-homocysteine (SAH or AdoHcy) (B). The transferred methyl group $\left(-\mathrm{CH}_{3}\right)$ is indicated by an arrow.

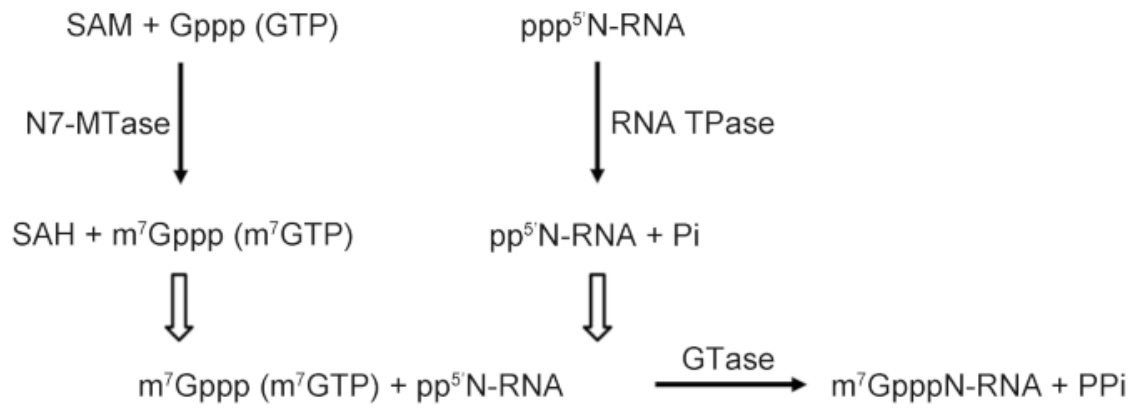

Figure 5. Reaction scheme of Alphaviridae-like non-conventional RNA capping. Solid arrows represent the direction of reactions. Unfilled arrows show the reaction sequence.

1981). They digested the ${ }^{32} \mathrm{P}$-labeled 60S MHV RNA with a mixture of RNases A, T1, and T2 and electrophoresed the digest on DEAE-cellulose paper to visualize the cap structure (Lai and Stohlman, 1981). They further showed that all of the viral RNAs contain 5'-cap structures, and at least four nucleotides immediately adjacent to the cap structures were identified as MHV-specific RNAs (Lai et al., 1982). Two decades later, van Vliet et al. purified the mRNAs of equine Berne torovirus (BEV) (Coronaviridae family) by immunoprecipitation with a cap-specific mouse antibody and identified them by northern blotting analysis (van Vliet et al., 2002), which also implied the existence of a cap structure for toroviral RNAs. However, CoVs replicate in the cytoplasm and thus cannot access the host capping machinery in the nucleus. Therefore, CoVs must have evolved to encode their own capping and methylation apparatus or otherwise hijack the cellular machinery.

\section{RNA TRIPHOSPHATASE (TPase)}

RNA TPase cleaves the inter-phosphate bond between the $\beta$ - and $\gamma$-phosphates and removes the $\gamma$-phosphate from the 5'-pppN of the nascent mRNA chain to generate $5^{\prime}$-ppN. Ivanov et al. showed that nsp13 of human $\mathrm{CoV}$ (HCoV)-229E and SARS-CoV exhibits nucleoside triphosphatase (NTPase) activities in vitro and, using its NTPase active site, mediates RNA 5'-TPase activity (Ivanov et al., 2004; Ivanov and Ziebuhr, 2004). We screened all the proteins encoded by CoVs for TPase activity using yeast strain YBS20 (cet1), which lacks the chromosomal CET1 locus encoding yeast RNA TPase and therefore depends on the RNA TPase function of the screened coronaviral gene for growth. Unfortunately, although expression of mouse capping enzyme (Mce1) stimulated growth, none of the viral genes could sustain the growth of YBS20 (Chen et al., 2009). This might indicates that the yeast mRNA capping machinery could not use the viral gene due to the diversified organization and mechanisms of RNA virus-capping apparatus, the subcellular location or the misfolding of the viral protein in yeast cells. Interestingly, CoV nsp 13 encodes both RNA helicase and triphosphatase (Tanner et al., 2003; Ivanov et al., 2004). As for many other RNA viruses, the RNA TPase is usually associated with RNA helicase activity. Therefore, nsp13 is proposed to be functional in the RNA capping reaction, but its direct role in coronaviral RNA capping still awaits experimental evidence.

\section{RNA GUANYLYLTRANSFERASE (GTase)}

RNA GTase could form a covalent link with a GMP (in conventional RNA capping pathway) or methylated GMP ( $\mathrm{m}^{7} \mathrm{GMP}$ ) (in Alphaviridae-like RNA capping pathway) and transfers it to the mRNA 5'-ppN to yield the cap core structure $(\mathrm{GpppN})$ or cap-0 structure $\left(\mathrm{m}^{7} \mathrm{GpppN}\right)$, respectively (Ahola and Ahlquist, 1999; De- 
croly et al., 2012). So far, there is neither experimental evidence nor bioinformatic prediction to demonstrate the existence of CoV GTase. Using a functional screening system similar to that for TPase activity, all the proteins coded by CoVs were screened for GTase activity using yeast strain YBS2 (cegl), which lacks the chromosomal CEG1 locus encoding the yeast GTase (Chen et al., 2009). Moreover, nsp7, nsp8, nsp10, and nsp12-16 of SARS-CoV were expressed and purified. The ability of each nsp to form a covalent linkage with GMP was tested using ${ }^{32}$ P-labeled GTP (Jin et al., 2013). Unfortunately, all attempts failed to identify the GTase involved in CoV RNA capping.

\section{(GUANINE-N7)-METHYLTRANSFERASE (N7-MTase)}

N7-MTase methylates the capping guanylate at the N7 position to produce a cap-0 structure $\left(\mathrm{m}^{7} \mathrm{GpppN}\right)$. N7methylation at guanylate could stabilize the $5^{\prime}$-end cap structure of mRNAs to avoid the reverse reaction associated with GTase mentioned above.

Functional screening of viral proteins using yeast strain YBS40, which is missing the chromosomal Abdl locus encoding the yeast cap MTase, revealed that SARS-CoV nsp14 sustains cell growth, indicating that nsp14 can act as an N7-MTase in cells (Chen et al., 2009). In vitro biochemical assays were used to further identify the N7-MTase activity of SARS-CoV nsp14. RNA substrates GpppA-RNA and GpppG-RNA were digested by nuclease P1 (which cleaves capped RNAs into 3'-OH-terminated cap structures and 5'-pNOH) or tobacco acid pyrophosphatase (TAP, which releases $\mathrm{m}^{7} \mathrm{Gp}$ and $\mathrm{Gp}$ from $\mathrm{m}^{\mathrm{GpppN}}$ ), respectively, and all of the results indicated that nsp14 was a sequence-nonspecific cap MTase (Chen et al., 2009). Moreover, the N7-MTase activity of nsp14 is highly conserved within Coronavirinae, at least in the representative CoVs from each genus (Sun et al., 2014). Interestingly, further study has revealed that $\mathrm{CoV}$ nsp14 can methylate different types of substrates, including GTP, dGTP, and cap analogs (GpppA, GppppG, and $\mathrm{m}^{7} \mathrm{GpppG}$ ) (Jin et al., 2013). The characteristics of the nsp14 N7-MTase suggest two possibilities for the CoV RNA capping pathway: Alphaviridae-like (Figure 5) or the conventional RNA capping pathway (Figure 3).

Notably, CoV nsp14 has been identified as a unique ExoN encoded by an RNA virus (Minskaia et al., 2006; Chen et al., 2007) and may work as an RNA proofreading enzyme (Eckerle et al., 2007; Eckerle et al., 2010; Smith et al., 2013; Smith et al., 2015). From a coronaviral protein-protein interaction matrix, nsp10 was shown to interact with nsp14 and nsp16 (Pan et al., 2008). The ExoN activity of nsp14 is significantly enhanced ( $>35$ fold) in the presence of the cofactor nsp10; the latter does not affect the N7-MTase activity of nsp14 (Bouvet et al., 2010; Bouvet et al., 2012). To understand the structure-function relationship between the ExoN and N7-MTase activities of nsp14, sequence alignment and comparison of conserved motifs were used to demonstrate that the core domains of the ExoN and N7-MTase were located at the $\mathrm{N}$ - and $\mathrm{C}$-termini of nsp14, respectively, and the core catalytic domains are distinct from each other. However, their functions are structurally linked, and the global structure of amino acids 62-527 of nsp14 is essential for both N7-MTase and ExoN activities (Chen et al., 2009; Chen et al., 2013). Recently, the crystal structure of the SARS-CoV nsp14/nsp10 complex was determined (Ma et al., 2015). The ExoN domain (amino acids 1-287) with a DEEDh catalytic motif and the N7-MTase domain (amino acids 288-527) with a DxGxPxG/A SAM-binding/catalytic motif could be distinguished clearly in the structure. The structure reveals 1:1 stoichiometry, where nsp10 binds exclusively with the ExoN domain of nsp14, which is highly similar to its traditional eukaryotic and prokaryotic predecessors. However, the N7-MTase domain exhibits a noncanonical MTase fold with a rare $\beta$-sheet insertion and a peripheral zinc finger, which is not essential for the N7MTase activity (Ma et al., 2015). Although the crystal structure of nsp14 confirmed some of the previous biochemical results indicating important residues and motifs (Bouvet et al., 2012; Chen et al., 2013), further biochemical and crystallographic analyses are required to reveal the mechanisms of this unique viral protein.

The combination of the two interdependently functional domains, an ExoN domain with proofreading function for the RNA virus and an atypical MTase domain with N7-MTase function conserved among Coronaviridae, indicates that the CoV N7-MTase is a novel RNA-processing enzyme and thus suggests it as an attractive target for the development of antiviral drugs. Shuman et al. creatively demonstrated that the mRNA capping functions in yeast cells can be replaced by the cap-forming enzymes from mammals (Mcel and Hcm1) or DNA viruses (composed of catalytic vD1-C and stimulatory vD12 subunits of vaccinia virus capping enzyme) (Saha et al., 1999; Ho et al., 2000; Saha et al., 2003), and we found that $\mathrm{CoV}$ nsp14 could replace the yeast cap N7MTase in vivo (Chen et al., 2009). Therefore, a yeast genetic system as a high-throughput enzymatic activity assay platform for various N7-MTases was established to identify CoV N7-MTase inhibitors (Sun et al., 2014).

\section{RIBOSE 2'-O-METHYLTRANSFERASE (2'-O-MTase)}

Ribose $2^{\prime}-O$-MTase methylates the cap- 0 structure at the ribose $2^{\prime}-O$ position of the first and second nucleotides of the mRNA to form the cap -1 ( $\left.\mathrm{m}^{7} \mathrm{GpppNm}\right)$ and cap-2 
$\left(\mathrm{m}^{7} \mathrm{GpppNmpNm}\right)$ structures, respectively. 2'-O methylation allows the viral RNA to evade the recognition of host RNA sensors such as RIG-I and Mda-5 (Hornung et al., 2006; Zust et al., 2011; Abbas et al., 2013; Bowzard et al., 2013) and to resist the interferon (IFN)-mediated antiviral response related to IFIT1/2 (Nallagatla et al., 2008; Daffis et al., 2010; Rehwinkel et al., 2010).

Soon after the SARS-CoV outbreak in 2003, bioinformatic prediction suggested that SARS-CoV nsp16 might possess SAM-dependent 2'-O-MTase activity (Snijder et al., 2003; von Grotthuss et al., 2003). However, only feline coronavirus (FCoV) showed a low level of 2'$O$-MTase activity (Decroly et al., 2008). Interestingly, as nsp10 can interact with nsp14 and nsp16 (Pan et al., 2008), Bouvet et al. demonstrated that the 2'-O-MTase activity of SARS-CoV nsp16 could be activated and stimulated by nsp10 (Bouvet et al., 2010), which is similar to the capping enzyme D1-D12 complex of vaccinia virus (Mao and Shuman, 1994; De la Pena et al., 2007). The SARS-CoV nsp16/10 complex could specifically synthesize the cap-1 structure using the cap- 0 structure RNA initiated with adenosine (m GpppA-RNA) as a substrate (Chen et al., 2011). Moreover, the stimulation mechanism of the SARS-CoV nsp16/10 complex is highly conserved among Coronaviridae including FCoV, and the stimulatory function of nsp10 is interchangeable among different CoVs (Wang et al., 2015). The crystal structure of the SARS-CoV nsp16/10 complex was reported by two research groups (Chen et al., 2011; Decroly et al., 2011). Biochemical and crystallographic analyses revealed that nsp10 acts as the stimulatory factor of nsp16 by stabilizing the SAM-binding pocket and extending the substrate RNA-binding groove of nsp16 (Chen et al., 2011). The conserved K-D-K-E catalytic tetrad motif located in the bottom of the RNA binding pocket and other critical residues such as the interface of the nsp16/10 complex were identified by biochemical assays and confirmed in the crystal structure (Bouvet et al., 2010; Chen et al., 2011; Decroly et al., 2011). Interestingly, the interfaces of nsp14/10 and nsp16/10 overlap on the surface of nsp10 (Chen et al., 2011; Decroly et al., 2011; Ma et al., 2015), indicating that one molecule of nsp10 could bind with one molecule of nsp14 or nsp16. To date, there is no evidence for the existence of an nsp14/10/16 complex in virus-infected cells.

Although, MTase inhibitors such as sinefungin, SAH (the byproduct of methylation), and aurintricarboxylic acid (ATA) suppressed coronaviral MTase activity (Bouvet et al., 2010; Sun et al., 2014), they are not ideal antiviral compounds because of their nonspecific inhibition of MTases. However, interference of the interaction between SARS-CoV nsp10 and nsp16 using short peptides could specifically inhibit the 2 '-O-MTase activity (Ke et al., 2012). Furthermore, because of the conserved stimulation mechanism of CoV nsp 16/10 complexes, an optimized peptide derived from the conserved interaction domain of MHV nsp10 showed broad-spectrum inhibition of 2'-O-MTase activity in vitro and virus replication in vivo for different CoVs (Wang et al., 2015). Notably, the peptide inhibitor exerted robust inhibitory effects in vivo in MHV-infected mice by impairing MHV virulence and pathogenesis through suppression of viral replication and enhancement of type I IFN production at an early stage of infection (Wang et al., 2015).

\section{DISCUSSION}

CoVs are the largest known RNA viruses, and their genomic RNAs might be the largest RNA molecules in the cellular cytoplasm. Therefore, CoVs evolved a relatively complicated replication mechanism to facilitate virus reproduction. Although, the 5'-ends of coronaviral RNAs were identified to be capped and methylated to mimic the cellular mRNA over three decades ago, the mechanism of CoV RNA capping and methylation requires further elucidation. Based on the summarization in this review, there are two cap assembly lines $\mathrm{CoV}$ might adopt: Alphaviridae-like (Figure 5) or the conventional RNA capping pathway (Figure 3), as the N7-MTase can methylate GTP as well as cap the core structure (GpppA- or GpppG-RNA). Identification of the CoV GTase will help resolve this question. In addition, the structure and direct evidence of nsp13 as an RNA TPase involved in viral RNA capping are still required. It is known that most eukaryotic viral mRNAs contain the same cap structure as that of cellular mRNAs. The degree of methylation on viral mRNA caps correlates with host mRNA cap methylation (Furuichi, 2015). This might help us to understand why $\mathrm{CoV}$ viral RNAs possess the cap-1 structure.

Recently, the novel functions of viral RNA cap structures in mammalian cell have been demonstrated: (i) the cap- 0 structure protects the 5 '-pppN from activating the host innate immune response (Pichlmair et al., 2006), (ii) the cap- 0 structure is essential for viral replication through the enhancement of viral RNA translation (Ray et al., 2006), (iii) the cap-1 structure allows evasion of recognition by the host innate immune system (Hornung et al., 2006; Zust et al., 2011; Abbas et al., 2013; Bowzard et al., 2013), and (iv) the cap-1 structure helps viruses resist the IFN-mediated antiviral response (Nallagatla et al., 2008; Daffis et al., 2010; Rehwinkel et al., 2010).

The critical role of the viral RNA cap structure and the distinct mechanisms of host and viral RNA capping have opened new opportunities for vaccine and antiviral drug development (Woyciniuk et al., 1995; Schwer et al., 2001; Chrebet et al., 2005; Ferron et al., 2012). Therefore, further studies on the mechanisms and characterist- 
ics of coronaviral RNA capping and methylation will promote the development of specific antiviral inhibitors and novel vaccines.

\section{ACKNOWLEDGMENTS}

This research was supported by the China "973" Basic Research Program (2013CB911101) and China NSFC grants (81130083 and 81271817).

\section{COMPLIANCE WITH ETHICS GUIDELINES}

The authors declare that they have no competing interest. This article does not contain any studies with human or animal subjects performed by any of the authors.

\section{REFERENCES}

Abbas YM, Pichlmair A, Gorna MW, Superti-Furga G, Nagar B. 2013. Structural basis for viral 5'-PPP-RNA recognition by human IFIT proteins. Nature, 494: 60-64.

Adams MJ, Carstens EB. 2012. Ratification vote on taxonomic proposals to the International Committee on Taxonomy of Viruses. Arch Virol, 157: 1411-1422.

Ahola T, Ahlquist P. 1999. Putative RNA capping activities encoded by brome mosaic virus: methylation and covalent binding of guanylate by replicase protein 1a. J Virol, 73: 1006110069.

Ahola T, Kaariainen L. 1995. Reaction in alphavirus mRNA capping: formation of a covalent complex of nonstructural protein nsP1 with 7-methyl-GMP. Proc Natl Acad Sci USA, 92: 507-511.

Banerjee AK. 1980. 5'-terminal cap structure in eucaryotic messenger ribonucleic acids. Microbiol Rev, 44: 175-205.

Bhardwaj K, Guarino L, Kao CC. 2004. The severe acute respiratory syndrome coronavirus Nsp 15 protein is an endoribonuclease that prefers manganese as a cofactor. J Virol, 78: 1221812224.

Bouvet M, Debarnot C, Imbert I, Selisko B, Snijder EJ, Canard B, Decroly E. 2010. In vitro reconstitution of SARS-coronavirus mRNA cap methylation. PLoS Pathog, 6: e1000863.

Bouvet M, Imbert I, Subissi L, Gluais L, Canard B, Decroly E. 2012. RNA 3'-end mismatch excision by the severe acute respiratory syndrome coronavirus nonstructural protein nsp10/nsp14 exoribonuclease complex. Proc Natl Acad Sci USA, 109: 9372-9377.

Bowzard JB, Ranjan P, Sambhara S. 2013. RIG-I goes beyond naked recognition. Cell Host Microbe, 13: 247-249.

Brierley I, Digard P, Inglis SC. 1989. Characterization of an efficient coronavirus ribosomal frameshifting signal: requirement for an RNA pseudoknot. Cell, 57: 537-547.

Cauchemez S, Van Kerkhove MD, Riley S, Donnelly CA, Fraser C, Ferguson NM. 2013. Transmission scenarios for Middle East Respiratory Syndrome Coronavirus (MERS-CoV) and how to tell them apart. Euro Surveill, 18: 20503.

Chen P, Jiang M, Hu T, Liu Q, Chen XS, Guo D. 2007. Biochemical characterization of exoribonuclease encoded by SARS coronavirus. J Biochem Mol Biol, 40: 649-655.

Chen Y, Cai H, Pan J, Xiang N, Tien P, Ahola T, Guo D. 2009. Functional screen reveals SARS coronavirus nonstructural protein nsp14 as a novel cap N7 methyltransferase. Proc Natl Acad
Sci USA, 106: 3484-3489.

Chen Y, Su C, Ke M, Jin X, Xu L, Zhang Z, Wu A, Sun Y, Yang Z, Tien P, Ahola T, Liang Y, Liu X, Guo D. 2011. Biochemical and structural insights into the mechanisms of SARS coronavirus RNA ribose $2^{\prime}-\mathrm{O}$-methylation by nsp16/nsp10 protein complex. PLoS Pathog, 7: e1002294.

Chen Y, Tao J, Sun Y, Wu A, Su C, Gao G, Cai H, Qiu S, Wu Y, Ahola T, Guo D. 2013. Structure-function analysis of severe acute respiratory syndrome coronavirus RNA cap guanine-N7methyltransferase. J Virol, 87: 6296-6305.

Chrebet GL, Wisniewski D, Perkins AL, Deng Q, Kurtz MB, Marcy A, Parent SA. 2005. Cell-based assays to detect inhibitors of fungal mRNA capping enzymes and characterization of sinefungin as a cap methyltransferase inhibitor. J Biomol Screen, 10: 355-364.

Cowling VH. 2010. Regulation of mRNA cap methylation. Biochem J, 425: 295-302.

Daffis S, Szretter KJ, Schriewer J, Li J, Youn S, Errett J, Lin TY, Schneller S, Zust R, Dong H, Thiel V, Sen GC, Fensterl V, Klimstra WB, Pierson TC, Buller RM, Gale M, Jr., Shi PY, Diamond MS. 2010. 2'-O methylation of the viral mRNA cap evades host restriction by IFIT family members. Nature, 468 : 452-456.

Darnell JE, Jr. 1979. Transcription units for mRNA production in eukaryotic cells and their DNA viruses. Prog Nucleic Acid Res Mol Biol, 22: 327-353.

De la Pena M, Kyrieleis OJ, Cusack S. 2007. Structural insights into the mechanism and evolution of the vaccinia virus mRNA cap N7 methyl-transferase. EMBO J, 26: 4913-4925.

Decroly E, Debarnot C, Ferron F, Bouvet M, Coutard B, Imbert I, Gluais L, Papageorgiou N, Sharff A, Bricogne G, Ortiz-Lombardia M, Lescar J, Canard B. 2011. Crystal Structure and Functional Analysis of the SARS-Coronavirus RNA Cap 2'-OMethyltransferase nsp10/nsp16 Complex. PLoS Pathog, 7: e1002059.

Decroly E, Ferron F, Lescar J, Canard B. 2012. Conventional and unconventional mechanisms for capping viral mRNA. Nat Rev Microbiol, 10: 51-65.

Decroly E, Imbert I, Coutard B, Bouvet M, Selisko B, Alvarez K, Gorbalenya AE, Snijder EJ, Canard B. 2008. Coronavirus nonstructural protein 16 is a cap- 0 binding enzyme possessing (nucleoside-2'O)-methyltransferase activity. J Virol, 82: 8071-8084.

Eckerle LD, Becker MM, Halpin RA, Li K, Venter E, Lu X, Scherbakova S, Graham RL, Baric RS, Stockwell TB, Spiro DJ, Denison MR. 2010. Infidelity of SARS-CoV Nsp14-exonuclease mutant virus replication is revealed by complete genome sequencing. PLoS Pathog, 6: e1000896.

Eckerle LD, Lu X, Sperry SM, Choi L, Denison MR. 2007. High fidelity of murine hepatitis virus replication is decreased in nsp14 exoribonuclease mutants. J Virol, 81: 12135-12144.

Enserink M. 2003. Infectious diseases. Clues to the animal origins of SARS. Science, 300: 1351.

Ferron F, Decroly E, Selisko B, Canard B. 2012. The viral RNA capping machinery as a target for antiviral drugs. Antiviral Res, 96: $21-31$.

Furuichi Y. 2015. Discovery of m(7)G-cap in eukaryotic mRNAs. Proc Jpn Acad Ser B Phys Biol Sci, 91: 394-409.

Furuichi Y, Shatkin AJ. 2000. Viral and cellular mRNA capping: past and prospects. Adv Virus Res, 55: 135-184.

Ge XY, Li JL, Yang XL, Chmura AA, Zhu G, Epstein JH, Mazet JK, Hu B, Zhang W, Peng C, Zhang YJ, Luo CM, Tan B, Wang N, Zhu Y, Crameri G, Zhang SY, Wang LF, Daszak P, Shi ZL. 2013. Isolation and characterization of a bat SARS-like coronavirus that uses the ACE2 receptor. Nature, 503: 535-538.

Gonzalez JM, Gomez-Puertas P, Cavanagh D, Gorbalenya AE, Enjuanes L. 2003. A comparative sequence analysis to revise 
the current taxonomy of the family Coronaviridae. Arch Virol, 148: 2207-2235.

Gorbalenya AE, Enjuanes L, Ziebuhr J, Snijder EJ. 2006. Nidovirales: evolving the largest RNA virus genome. Virus Res, 117: 17-37.

Ho CK, Martins A, Shuman S. 2000. A yeast-based genetic system for functional analysis of viral mRNA capping enzymes. J Virol, 74: 5486-5494.

Hornung V, Ellegast J, Kim S, Brzozka K, Jung A, Kato H, Poeck H, Akira S, Conzelmann KK, Schlee M, Endres S, Hartmann G. 2006. 5'-Triphosphate RNA is the ligand for RIG-I. Science, 314: 994-997.

Hussain S, Pan J, Chen Y, Yang Y, Xu J, Peng Y, Wu Y, Li Z, Zhu Y, Tien P, Guo D. 2005. Identification of novel subgenomic RNAs and noncanonical transcription initiation signals of severe acute respiratory syndrome coronavirus. J Virol, 79: 5288-5295.

Imbert I, Guillemot JC, Bourhis JM, Bussetta C, Coutard B, Egloff MP, Ferron F, Gorbalenya AE, Canard B. 2006. A second, noncanonical RNA-dependent RNA polymerase in SARS coronavirus. Embo J, 25: 4933-4942.

Ivanov KA, Thiel V, Dobbe JC, van der Meer Y, Snijder EJ, Ziebuhr J. 2004. Multiple enzymatic activities associated with severe acute respiratory syndrome coronavirus helicase. J Virol, 78: 5619-5632.

Ivanov KA, Ziebuhr J. 2004. Human coronavirus 229E nonstructural protein 13: characterization of duplex-unwinding, nucleoside triphosphatase, and RNA 5'-triphosphatase activities. J Virol, 78: 7833-7838.

Jin H, Elliott RM. 1993. Characterization of Bunyamwera virus $S$ RNA that is transcribed and replicated by the L protein expressed from recombinant vaccinia virus. J Virol, 67: 13961404.

Jin X, Chen Y, Sun Y, Zeng C, Wang Y, Tao J, Wu A, Yu X, Zhang Z, Tian J, Guo D. 2013. Characterization of the guanineN7 methyltransferase activity of coronavirus nsp14 on nucleotide GTP. Virus Res, 176: 45-52.

Joseph JS, Saikatendu KS, Subramanian V, Neuman BW, Buchmeier MJ, Stevens RC, Kuhn P. 2007. Crystal structure of a monomeric form of severe acute respiratory syndrome coronavirus endonuclease nsp15 suggests a role for hexamerization as an allosteric switch. J Virol, 81: 6700-6708.

Ke M, Chen Y, Wu A, Sun Y, Su C, Wu H, Jin X, Tao J, Wang Y, Ma X, Pan JA, Guo D. 2012. Short peptides derived from the interaction domain of SARS coronavirus nonstructural protein nsp10 can suppress the 2'-O-methyltransferase activity of nsp10/nsp16 complex. Virus Res, 167: 322-328.

Lai MM, Patton CD, Stohlman SA. 1982. Further characterization of mRNA's of mouse hepatitis virus: presence of common 5'end nucleotides. J Virol, 41: 557-565.

Lai MM, Stohlman SA. 1981. Comparative analysis of RNA genomes of mouse hepatitis viruses. J Virol, 38: 661-670.

Leahy MB, Dessens JT, Nuttall PA. 1997. In vitro polymerase activity of Thogoto virus: evidence for a unique cap-snatching mechanism in a tick-borne orthomyxovirus. J Virol, 71: 83478351.

Li W, Shi Z, Yu M, Ren W, Smith C, Epstein JH, Wang H, Crameri G, Hu Z, Zhang H, Zhang J, McEachern J, Field H, Daszak P, Eaton BT, Zhang S, Wang LF. 2005. Bats are natural reservoirs of SARS-like coronaviruses. Science, 310: 676-679.

Liu H, Kiledjian M. 2006. Decapping the message: a beginning or an end. Biochem Soc Trans, 34: 35-38.

Ma Y, Wu L, Shaw N, Gao Y, Wang J, Sun Y, Lou Z, Yan L, Zhang R, Rao Z. 2015. Structural basis and functional analysis of the SARS coronavirus nsp14-nsp10 complex. Proc Natl Acad
Sci USA, 112: 9436-9441.

Mao X, Shuman S. 1994. Intrinsic RNA (guanine-7) methyltransferase activity of the vaccinia virus capping enzyme D1 subunit is stimulated by the D12 subunit. Identification of amino acid residues in the D1 protein required for subunit association and methyl group transfer. J Biol Chem, 269: 24472-24479.

Martina BE, Haagmans BL, Kuiken T, Fouchier RA, Rimmelzwaan GF, Van Amerongen G, Peiris JS, Lim W, Osterhaus AD. 2003. Virology: SARS virus infection of cats and ferrets. Nature, 425: 915.

Martinez-Salas E, Pineiro D, Fernandez N. 2012. Alternative Mechanisms to Initiate Translation in Eukaryotic mRNAs. Comp Funct Genomics, 2012: 391546.

Minskaia E, Hertzig T, Gorbalenya AE, Campanacci V, Cambillau C, Canard B, Ziebuhr J. 2006. Discovery of an RNA virus $3^{\prime} \rightarrow 5^{\prime}$ exoribonuclease that is critically involved in coronavirus RNA synthesis. Proc Natl Acad Sci U S A, 103: 5108-5113.

Mizutani T. 2013. A novel coronavirus, MERS-CoV. Uirusu, 63: 1-6. (In Japanese)

Nallagatla SR, Toroney R, Bevilacqua PC. 2008. A brilliant disguise for self RNA: 5'-end and internal modifications of primary transcripts suppress elements of innate immunity. RNA Biol, 5: 140-144.

Ogino T, Banerjee AK. 2007. Unconventional mechanism of mRNA capping by the RNA-dependent RNA polymerase of vesicular stomatitis virus. Mol Cell, 25: 85-97.

Pan J, Peng X, Gao Y, Li Z, Lu X, Chen Y, Ishaq M, Liu D, Dediego ML, Enjuanes L, Guo D. 2008. Genome-wide analysis of protein-protein interactions and involvement of viral proteins in SARS-CoV replication. PLoS One, 3: e3299.

Pelletier J, Sonenberg N. 1988. Internal initiation of translation of eukaryotic mRNA directed by a sequence derived from poliovirus RNA. Nature, 334: 320-325.

Pichlmair A, Schulz O, Tan CP, Naslund TI, Liljestrom P, Weber F, Reis e Sousa C. 2006. RIG-I-mediated antiviral responses to single-stranded RNA bearing 5'-phosphates. Science, 314: 997-1001.

Prentice E, McAuliffe J, Lu X, Subbarao K, Denison MR. 2004. Identification and characterization of severe acute respiratory syndrome coronavirus replicase proteins. J Virol, 78: 99779986.

Ray D, Shah A, Tilgner M, Guo Y, Zhao Y, Dong H, Deas TS, Zhou Y, Li H, Shi PY. 2006. West Nile virus 5'-cap structure is formed by sequential guanine N-7 and ribose 2'-O methylations by nonstructural protein 5. J Virol, 80: 8362-8370.

Rehwinkel J, Tan CP, Goubau D, Schulz O, Pichlmair A, Bier K, Robb N, Vreede F, Barclay W, Fodor E, Reis e Sousa C. 2010. RIG-I detects viral genomic RNA during negative-strand RNA virus infection. Cell, 140: 397-408.

Saha N, Schwer B, Shuman S. 1999. Characterization of human, Schizosaccharomyces pombe, and Candida albicans mRNA cap methyltransferases and complete replacement of the yeast capping apparatus by mammalian enzymes. J Biol Chem, 274: 16553-16562.

Saha N, Shuman S, Schwer B. 2003. Yeast-based genetic system for functional analysis of poxvirus mRNA cap methyltransferase. J Virol, 77: 7300-7307.

Sawicki SG, Sawicki DL, Younker D, Meyer Y, Thiel V, Stokes H, Siddell SG. 2005. Functional and genetic analysis of coronavirus replicase-transcriptase proteins. PLoS Pathog, 1: e39.

Schwer B, Lehman K, Saha N, Shuman S. 2001. Characterization of the mRNA capping apparatus of Candida albicans. J Biol Chem, 276: 1857-1864.

Schwer B, Mao X, Shuman S. 1998. Accelerated mRNA decay in 
conditional mutants of yeast mRNA capping enzyme. Nucleic Acids Res, 26: 2050-2057.

Sevajol M, Subissi L, Decroly E, Canard B, Imbert I. 2014. Insights into RNA synthesis, capping, and proofreading mechanisms of SARS-coronavirus. Virus Res, 194: 90-99.

Shatkin AJ. 1976. Capping of eucaryotic mRNAs. Cell, 9: 645-653.

Shuman S. 2001. Structure, mechanism, and evolution of the mRNA capping apparatus. Prog Nucleic Acid Res Mol Biol, 66: $1-40$.

Smith EC, Blanc H, Surdel MC, Vignuzzi M, Denison MR. 2013. Coronaviruses lacking exoribonuclease activity are susceptible to lethal mutagenesis: evidence for proofreading and potential therapeutics. PLoS Pathog, 9: e1003565.

Smith EC, Case JB, Blanc H, Isakov O, Shomron N, Vignuzzi M, Denison MR. 2015. Mutations in coronavirus nonstructural protein 10 decrease virus replication fidelity. J Virol, 89: 64186426.

Snijder EJ, Bredenbeek PJ, Dobbe JC, Thiel V, Ziebuhr J, Poon LL, Guan Y, Rozanov M, Spaan WJ, Gorbalenya AE. 2003. Unique and conserved features of genome and proteome of SARS-coronavirus, an early split-off from the coronavirus group 2 lineage. J Mol Biol, 331: 991-1004.

Sun Y, Wang Z, Tao J, Wang Y, Wu A, Yang Z, Wang K, Shi L, Chen Y, Guo D. 2014. Yeast-based assays for the high-throughput screening of inhibitors of coronavirus RNA cap guanineN7-methyltransferase. Antiviral Res, 104: 156-164.

Tanner JA, Watt RM, Chai YB, Lu LY, Lin MC, Peiris JS, Poon LL, Kung HF, Huang JD. 2003. The severe acute respiratory syndrome (SARS) coronavirus NTPase/helicase belongs to a distinct class of $5^{\prime}$ to $3^{\prime}$ viral helicases. J Biol Chem, 278: 39578-39582.

te Velthuis AJ, van den Worm SH, Snijder EJ. 2012. The SARScoronavirus nsp $7+n s p 8$ complex is a unique multimeric RNA polymerase capable of both de novo initiation and primer extension. Nucleic Acids Res, 40: 1737-1747.
Thiel V, Ivanov KA, Putics A, Hertzig T, Schelle B, Bayer S, Weissbrich B, Snijder EJ, Rabenau H, Doerr HW, Gorbalenya AE, Ziebuhr J. 2003. Mechanisms and enzymes involved in SARS coronavirus genome expression. J Gen Virol, 84: 23052315.

Tsukiyama-Kohara K, Iizuka N, Kohara M, Nomoto A. 1992. Internal ribosome entry site within hepatitis $\mathrm{C}$ virus RNA. J Virol, 66: $1476-1483$.

van Vliet AL, Smits SL, Rottier PJ, de Groot RJ. 2002. Discontinuous and non-discontinuous subgenomic RNA transcription in a nidovirus. Embo J, 21: 6571-6580.

von Grotthuss M, Wyrwicz LS, Rychlewski L. 2003. mRNA cap-1 methyltransferase in the SARS genome. Cell, 113: 701-702.

Wang LF, Shi Z, Zhang S, Field H, Daszak P, Eaton BT. 2006. Review of bats and SARS. Emerg Infect Dis, 12: 1834-1840.

Wang Y, Sun Y, Wu A, Xu S, Pan R, Zeng C, Jin X, Ge X, Shi Z, Ahola T, Chen Y, Guo D. 2015. Coronavirus nsp10/nsp16 Methyltransferase Can Be Targeted by nsp10-Derived Peptide In Vitro and In Vivo To Reduce Replication and Pathogenesis. J Virol, 89: 8416-8427.

Woyciniuk P, Linder M, Scholtissek C. 1995. The methyltransferase inhibitor Neplanocin A interferes with influenza virus replication by a mechanism different from that of 3-deazaadenosine. Virus Res, 35: 91-99.

Ziebuhr J. 2004. Molecular biology of severe acute respiratory syndrome coronavirus. Curr Opin Microbiol, 7: 412-419.

Zuniga S, Sola I, Alonso S, Enjuanes L. 2004. Sequence motifs involved in the regulation of discontinuous coronavirus subgenomic RNA synthesis. J Virol, 78: 980-994.

Zust R, Cervantes-Barragan L, Habjan M, Maier R, Neuman BW, Ziebuhr J, Szretter KJ, Baker SC, Barchet W, Diamond MS, Siddell SG, Ludewig B, Thiel V. 2011. Ribose 2'-O-methylation provides a molecular signature for the distinction of self and non-self mRNA dependent on the RNA sensor Mda5. Nat Immunol, 12: 137-143. 